\title{
Region-Wide Analysis of Genetic Diversity in Verticillium dahliae Populations Infecting Olive in Southern Spain and Agricultural Factors Influencing the Distribution and Prevalence of Vegetative Compatibility Groups and Pathotypes
}

\author{
Rafael M. Jiménez-Díaz, Concepción Olivares-García, Blanca B. Landa, \\ María del Mar Jiménez-Gasco, and Juan A. Navas-Cortés
}

First and second authors: Escuela Técnica Superior de Ingenieros Agrónomos y Montes, Universidad de Córdoba, Edificio C-4 'Celestino Mutis', Campus de Rabanales, Ctra. Madrid-Cádiz, km 396, 14071 Córdoba, Spain and Instituto de Agricultura Sostenible (IAS), Consejo Superior de Investigaciones Científicas (CSIC), Apartado 4084, 14080 Córdoba, Spain; third and fifth authors: IAS-CSIC; and fourth author: Department of Plant Pathology, The Pennsylvania State University, University Park, PA 16802.

Accepted for publication 6 October 2010.

\begin{abstract}
Jiménez-Díaz, R. M., Olivares-García, C., Landa, B. B., Jiménez-Gasco, M. M., and Navas-Cortés, J. A. 2011. Region-wide analysis of genetic diversity in Verticillium dahliae populations infecting olive in southern Spain and agricultural factors influencing the distribution and prevalence of vegetative compatibility groups and pathotypes. Phytopathology 101:304-315.

Severity of Verticillium wilt in olive trees in Andalusia, southern Spain is associated with the spread of a highly virulent, defoliating (D) Verticillium dahliae pathotype of vegetative compatibility group 1A (VCG1A) but the extent of this spread and the diversity of the pathogen population have never been documented. VCG typing of $637 \mathrm{~V}$. dahliae isolates from 433 trees in 65 orchards from five olive-growing provinces in Andalusia indicated that $78.1 \%$ were of VCG1A, $19.8 \%$ of VCG2A, $0.6 \%$ of $\mathrm{VCG} 2 \mathrm{~B}, 1.4 \%$ of VCG4B, and one isolate was heterokaryon selfincompatible. A single VCG prevailed among isolates within most orchards but two and three VCGs were identified in 12 and 3 orchards, respectively, with VCG1A+VCG2A occurring in 10 orchards. VCG1A was the predominant VCG in the three most important olive-growing provinces, and was almost as prevalent as VCG2A in another one. Molecular pathotyping of the 637 isolates using specific polymerase chain
\end{abstract}

ABSTRACT reaction assays indicated that VCG1A isolates were of the D pathotype whereas isolates of VCG2A, $-2 \mathrm{~B}$, and $-4 \mathrm{~B}$ were of the less virulent nondefoliating (ND) pathotype. The pathotype of isolates correlated with the disease syndrome affecting sampled trees. Only three (seq1, seq2, and seq4) of the seven known sequences of the $V$. dahliae-specific 539- or 523-bp amplicon were identified among the 637 isolates. Distribution and prevalence of VCGs and seq sequences among orchards indicated that genetic diversity within olive $V$. dahliae in Andalusia is higher in provinces where VCG1A is not prevalent. Log-linear analysis revealed that irrigation management, source of irrigation water, source of planting stock, and cropping history of soil were significantly associated with the prevalence of VCG1A compared with that of VCG2A. Multivariate analyses using a selected set of agricultural factors as variables allowed development of a discriminant model for predicting the occurrence of $\mathrm{D}$ and ND pathotypes in the area of the study. Blind tests using this model correctly indentified the $V$. dahliae pathotype occurring in an orchard. The widespread occurrence and high prevalence of VCG1A/D pathotype in Andalusia have strong implications for the management of the disease.

Additional keywords: discriminant analysis, DNA sequencing, molecular markers, Olea europaea, soil type.
Verticillium wilt (VW) of olive (Olea europaea L.) caused by Verticillium dahliae Kleb. is one of the most important diseases of this crop worldwide $(27,37,59)$. In Spain, the disease was first observed in 1979 in experimental fields near Córdoba, Andalusia, southern Spain (9). Subsequently, the pathogen has spread and now causes severe infections in olive throughout that region, as well as other regions in Spain $(52,54)$ (R. M. Jiménez-Díaz, unpublished data), making $\mathrm{VW}$ the main current threat for the Andalusia olive industry.

The increase in distribution and importance of VW of olive in Andalusia has occurred concomitant with both the expansion of the olive crop in this region, which has reached $\approx 65 \%$ of the olive acreage in Spain (41), and changes in cropping practices for increasing olive yields. These changes include use of self-rooted

Corresponding author: R. M. Jiménez-Díaz; E-mail address: ag1jidir@uco.es

* The $e$-Xtra logo stands for "electronic extra" and indicates that the online version contains a supplemental table.

doi:10.1094/PHYTO-07-10-0176

(c) 2011 The American Phytopathological Society planting stocks to establish high-tree-density, drip-irrigated orchards with reduced tillage and high inputs of fertilizers in newly cultivated soils or fertile soils previously cropped to $V$. dahliae hosts, such as cotton (62). Those changes in the management of olive crops have led to intensively managed orchards and may have played a role in the increased distribution and intensity of $\mathrm{VW}$ in olive in Andalusia. However, no information was available on the relationship that might exist between olive husbandry and the extent of the disease.

Severity of $V$. dahliae attacks on olive strongly depends on virulence of the pathogen isolates (here defined as the amount of disease caused on individual hosts or host genotypes). $V$. dahliae isolates infecting olive can be classified into defoliating (D) or nondefoliating (ND) pathotypes, based on their ability to cause defoliation or no defoliation of green leaves from shoots and twigs $(46,52)$. Infections by the D pathotype can be lethal to the plant, whereas ND-infected olive trees can eventually show complete remission from symptoms $(27,37,38,63)$. D and ND pathotypes also occur in $V$. dahliae infecting upland cotton (Gossypium hirsutum L.), with $\mathrm{D}$ and ND isolates from cotton and olive showing cross-virulence $(52,55)$. In Spain, the D pathotype was 
first reported infecting cotton in Seville province, southwestern Andalusia, in 1981 (3). This pathotype has since been reported in distant (up to $200 \mathrm{~km}$ ) olive-growing provinces of that region $(4,43)$ (R. M. Jiménez-Díaz, unpublished data) but the extent to which the D pathotype has spread in the olive-growing areas of Andalusia has not been documented yet.

Field populations of $V$. dahliae are considered to have a clonal structure, although a level of sexual recombination has recently been suggested to occur $(2,14,15)$. Thus, knowledge of the genetic diversity and structure in the pathogen populations and their relationships with virulence is a key factor for the management of VWs through disease prediction, development and deployment of resistant cultivars, and proper implementation of crop rotations. In spite of the widespread occurrence of VW in olive throughout Andalusia, little was known about the extent of genetic diversity in $V$. dahliae populations infecting olive across the region. Genetic diversity in $V$. dahliae has been studied mainly by analysis of vegetative compatibility groups (VCGs) using nitrate-nonutilizing (nit) mutants and analyses of the fungal DNA (14-16,25,31,43,53).

$V$. dahliae isolates in different VCGs are often thought of as genetically isolated populations which may vary in a number of ecological, physiological, and virulence traits $(31,53)$. Six VCGs (VCG1-VGC6) have been identified using $V$. dahliae isolates from diverse hosts and geographic origins worldwide $(5,7,11,28$, 31,57). VCG1, VCG2, and VCG4 were further divided into two subgroups (designated A and B) based on the frequency and vigor of complementation $(5,11,29,56)$. Isolates and nit mutant testers were described that represent the subgroups of those three VCGs $(28,29,56,57)$. The use of this set of isolates and nit mutant testers in VCG studies has helped in establishing an internationally uniform system for classification and exchange of information about VCGs in $V$. dahliae populations $(31,53)$. Vegetative compatibility in $V$. dahliae populations has been studied according to two main approaches: (i) using collections of isolates from diverse geographic origin and source plants and (ii) concentrating on populations occurring in particular geographic regions or specific crops. The few studies about VCGs associated with specific crops indicate that some VCGs may prevail on a crop in a given geographic area $(7,25,28,29,35,56,57)$. Moreover, these studies have led to recognition that VCG and virulence of $V$. dahliae isolates from a given crop may be correlated. For example, VCG1A isolates are more virulent to cotton than those in VCG2B and VCG4B (35); VCG2B isolates are more virulent to artichoke and mint than those in VCG1A (25) and VCG4A (30), respectively; and VCG4A isolates are the most virulent to potato (29). All VCG1A isolates from cotton and olive of different geographic origin are of the $\mathrm{D}$ pathotype whereas isolates of VCGs $2 \mathrm{~A}, 2 \mathrm{~B}$, or $4 \mathrm{~B}$ are of the ND pathotype $(5,11,15$, $19,20,25,35,36)$. VCG1B isolates from cotton or woody hosts were proved to be of the ND pathotype when tested on cotton $(5,11,15)$ (R. M. Jiménez-Díaz, unpublished data).

Phenetic analysis of amplified fragment length polymorphism (AFLP) fingerprinting indicated that AFLP clustering of $V$. dahliae isolates correlates with VCG subgroups regardless of host source and geographic origin of isolates (15). However, VCGs do not describe fully the overall genetic diversity that may exist within $V$. dahliae populations. High molecular variability occurred within VCGs, as indicated by AFLP and V. dahliae-specific DNA sequence analyses as well as by size classes of specific polymerase chain reaction (PCR) amplicons (13-16). Therefore, unravelling the genetic diversity within $V$. dahliae VCGs associated with VW of olive in Andalusia would be of importance to understand mechanisms underlying the pathogen spread through the region and for management of the disease. The main objectives of this study were to (i) determine VCG diversity among $V$. dahliae isolates from olive and their distribution in southern Spain, (ii) characterize those isolates by means of molecular markers previously associated with $\mathrm{D}$ and ND pathotypes as well as by DNA sequence analysis of a polymorphic $V$. dahliaespecific PCR amplicon, and (iii) reveal any association between the distribution pattern of $V$. dahliae VCGs and pathotypes from olive and agricultural factors that characterize olive husbandry and management in Andalusia. A preliminary summary of results from this study has been reported (26).

\section{MATERIALS AND METHODS}

VW surveys. In total, $65 \mathrm{VW}$-affected olive orchards were surveyed in the five most important olive-growing provinces in Andalusia-Córdoba (21 orchards), Granada (10 orchards), Huelva (four orchards), Jaén (16 orchards), and Seville (14 orchards) - in 2005 and 2006 (Fig. 1). Surveys were done in spring each year at the time when conditions are most appropriate for expression of disease symptoms and isolation of $V$. dahliae from affected olive trees $(27,37)$. Orchards were arbitrarily selected with the assistance of growers and extension agents. The incidence of VW in an orchard was estimated in 100 consecutive trees in each of four arbitrarily chosen rows. In all, 4 to 10 trees (depending upon disease incidence) showing symptoms characteristic of the disease (46) were arbitrarily chosen from each orchard for isolation of the pathogen. The disease syndrome affecting each of sampled trees was annotated and the tree location was recorded using geographical positioning equipment (Trimble, Sunnyvale, CA). In total, 433 olive trees were sampled for the study. Eight agricultural factors that are important in the development of VWs in many crops (48) were recorded from each of the sampled orchards: cropping history, crop age, olive cultivar, source of planting stock, tree density, irrigation management, source of irrigation water, and soil texture.

Procurement of $\boldsymbol{V}$. dahliae isolates and culture conditions. A collection of $637 \mathrm{~V}$. dahliae monoconidial isolates was studied (Table 1). Isolations were done from four young symptomatic branches per affected tree, as previously described (46). Cultures were incubated at $25 \pm 1{ }^{\circ} \mathrm{C}$ in the dark for 7 days. Pure cultures of $V$. dahliae were identified based on the morphology of conidiophores and microsclerotia formed on potato dextrose agar (PDA) (Difco Laboratories, Detroit). One or two monoconidial isolates were kept from 229 and 204 olive trees, respectively, for VCG characterization and molecular analyses. Cultures on plum-lactose-yeast extract agar (PLYA) (58) were covered with sterile mineral oil (4) and stored at $4^{\circ} \mathrm{C}$ in the dark. Isolates are deposited in the culture collection of Instituto de Agricultura Sostenible, CSIC, Córdoba, Spain, and the Department of Plant Pathology, The Pennsylvania State University, University Park, PA. Active cultures of isolates were obtained on water agar and further subculturing on Czapek-Dox agar (CDA; Difco Laboratories) at $25 \pm 1{ }^{\circ} \mathrm{C}$ in the dark.

Generation and characterization of nit mutants and determination of vegetative compatibility. All $637 \mathrm{~V}$. dahliae isolates were characterized to $\mathrm{VCG}$ by complementation tests of nit mutants, which were generated according to Korolev and Katan (33) and previous studies $(15,25)$ and phenotyped according to Correll et al. (17). Complementation tests were performed by pairing phenotypically distinct nit mutants of an isolate, as well as by pairing them with complementing nit mutants of the international Ohio Agricultural Research and Development Center (OARDC, The Ohio State University, Wooster) reference strains of $V$. dahliae VCGs (VCG1, -3, and -4A) and with Israeli nit testers (VCG1A, -2A, -2B, and -4B) (34) in all possible combinations. Testers used and complementation procedures were described in previous studies $(15,25)$. Israeli nit testers of VCG2A, VCG2B, and VCG4B were previously demonstrated to correlate with the international OARDC reference strains $(31,34,36,53)$. The nit mutants derived from reference strain T9 of D pathotype, kindly provided by T. Katan (The Volcani Center, Bet Dagan, Israel), were used to identify VCG1A. Because T9 belongs to 
VCG1A of Bell (5), we assumed that isolates strongly compatible with it should be assigned to VCG1A. The nit mutants of isolates 1990.1 and 9.6 (25) from Japanese maple and yellow wood, respectively, were used for the identification VCG1B $(5,11)$. These tester isolates were proved to be of the ND pathotype in virulence assays on cotton (R. M. Jiménez-Díaz, unpublished results). Cultures were incubated at $25 \pm 1{ }^{\circ} \mathrm{C}$ with a 12-h photoperiod of fluorescent and near-UV light at $36 \mu \mathrm{Em}^{-2} \mathrm{~s}^{-1}$ for up to 4 weeks. Pairings were scored for complementation according to Jiménez-Díaz et al. (25). Positive complementation reactions between tested isolates, or between an unknown and a tester strain, allowed the assignment of unknown isolates to the same VCG or to the VCG of the tester strain.

In a previous VCG study, some VCG2B $V$. dahliae isolates from artichoke failed to form heterokaryons with international reference testers of that VCG but did with selected local testers (25). Thus, in the present study, we adopted a two-step strategy for the characterization of $V$. dahliae isolates from olive to VCG. First, 131 isolates were characterized to VCG (VCG1A, 80 isolates; VCG2A, 40 isolates; VCG2B, 4 isolates; and VCG4B, 7 isolates) using OARDC reference strains and Israeli nit testers. Then, complementing nit mutants of isolates in each of VCGs were paired in all possible combinations to select local tester strains on the basis of strongest complementation. Thereafter, the remaining 506 isolated were assigned to VCG using the OARDC and Israeli tester strains as well as the local tester strains.
Molecular characterization of $\boldsymbol{V}$. dahliae isolates. All $637 \mathrm{~V}$. dahliae isolates in this study were characterized by means of PCR assays using primer pairs DB19/DB22 (10), INTD2f/2r and INTND2f/2r $(44,45)$, and DB19/DB22/espdf01 (43). The use of primers DB19/DB22 produces $V$. dahliae-specific polymorphic DNA bands of 539 or $523 \mathrm{bp}$. The 539-bp marker is present in D isolates of VCG1A and ND isolates of VCG1B, whereas the 523bp marker is associated with the ND pathotype regardless of VCG $(16,43)$. The joint use of primer pairs INTD2f/2r and INTND2f/2r produce amplicons of either 462 or 824 bp that previously were associated with the $\mathrm{D}$ and ND pathotypes of $V$. dahliae, respectively $(44,45)$. The use of primers DB19/DB22/espdef01 in a single reaction yields one of the 539- or 523-bp markers together with an amplicon of $334 \mathrm{bp}$ which is present in D isolates and also in some ND isolates of VCG1B and VCG2B $(16,43)$.

DNA extraction and determination of purity and concentration were as previously reported (15). DNA solutions were stored at $-20^{\circ} \mathrm{C}$ until use. Amplifications using the primer pairs referred to above, and separation and visualization of amplification products, were carried out according to Jiménez-Díaz et al. (25). All PCR assays were performed with a PTC-100 thermocycler (MJ Research, Inc., Watertown, MA). Reactions were repeated at least twice and always included negative controls (no DNA) as well as positive controls (template DNA from $V$. dahliae isolates representative of $\mathrm{D}$ [V138I isolate] and ND [V176I isolate] pathotypes from previous studies) (43-45). The correlation between molecular typing of

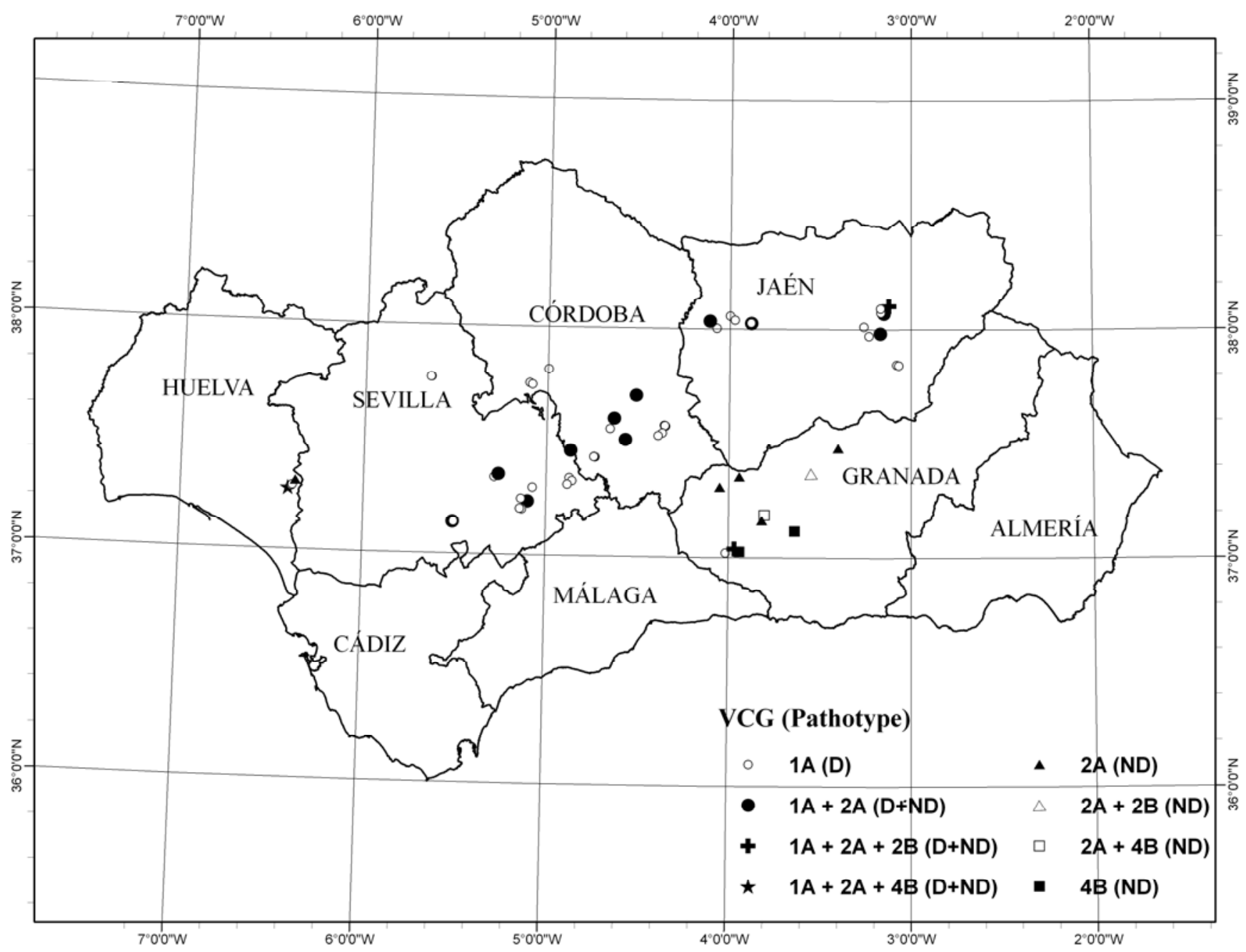

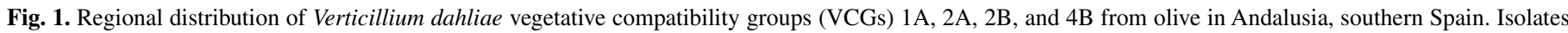

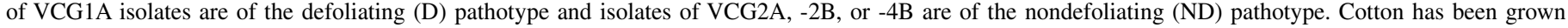

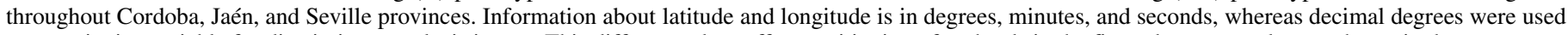
as quantitative variable for discriminate analysis in text. This difference does affect positioning of orchards in the figure because scales are shown in degrees. 
isolates into D or ND pathotypes and the disease syndrome affecting the tree from which they were obtained was examined. In addition, the pathotype of isolates was confirmed by root-dip inoculation of potted plants of olive cv. Picual using five arbitrarily chosen isolates of each of VCG1A (D isolates) and VCG2A, -2B, and -4B (ND isolates). $V$. dahliae isolates V138I and V1876I were used as control for pathotypes in those inoculations (24).

Sequencing of the polymorphic $V$. dahliae-specific amplicon. The polymorphic $V$. dahliae-specific DNA band amplified from the $637 \mathrm{~V}$. dahliae isolates in the study using primers DB19 and DB22 was sequenced. PCR products were purified using the AccuPrep PCR Purification kit (Bioneer, Seoul, Korea), quantified spectrophotometrically as described above, and used for direct sequencing with primer DB19. DNA sequencing was done on a multicapillary sequencer (Abiprism 3100 genetic analyzer; Applied Biosystems, Foster City, CA) at the University of Córdoba sequencing facilities. Sequences were aligned using Sequencher 4.1.4 software (Gene Codes Corporation, Ann Arbor,

TABLE 1. Isolates of Verticillium dahliae from olive in Andalusia, southern Spain, listed by vegetative compatibility group (VCG), number, geographic origin, molecular marker, DNA sequence type of a polymorphic V. dahliae-specific polymerase chain reaction (PCR) amplicon (seq), and pathotype

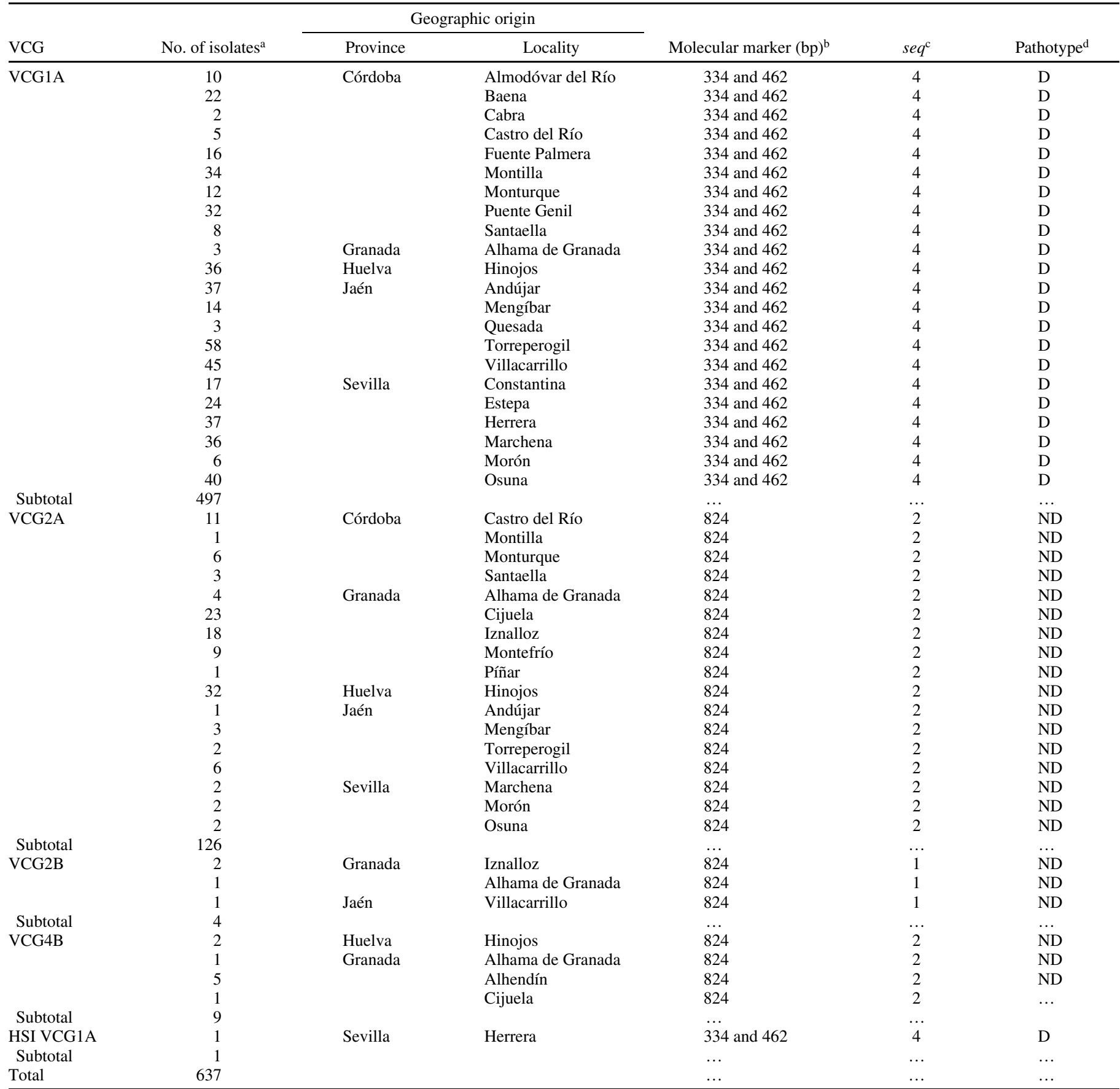

a Vegetative compatibility was determined using nitrate-nonutilizing mutants generated according to Korolev and Katan (33) and Correll et al. (17), and pairing them with complementary mutants of international Ohio Agricultural Research and Development Center reference and Israeli tester strains $(34,36,53)$. HSI $=$ heterokaryon self-incompatible.

b Amplicons produced in PCR assays using primer sets DB19/DB22/espdef018 (334 bp), INTD2f/INTD2r (462 bp), and INTND2f/INTND2r (824 bp) (43-45).

${ }^{c} V$. dahliae-specific sequence amplified in PCR assays using primer pair DB19/DB22 (10). $1=$ seq1 (527 bp); $2=$ seq2 (526 bp); $4=$ seq4 (542 bp) (14).

${ }^{\mathrm{d}} \mathrm{D}=$ olive and cotton defoliating, as indicated by amplification of the 462-bp marker; $\mathrm{ND}=$ olive and cotton nondefoliating, as indicated by amplification of $824-$ bp marker (43-45). 
MI) and compared with the seven polymorphic sequences of the 523- or 539-bp amplicons already described (13,14,16): seq1 (527 bp, GenBank accession no. DQ266246), seq2 (526 bp, DQ266247), seq3 (526 bp, DQ266248), seq4 (542 bp, DQ266249), seq5 (550 bp, AF363243), seq6 (543 bp, DQ266244), and seq7 (541 bp, DQ2666245).

Association among the distribution of $V$. dahliae VCGs and pathotypes from olive and variables that characterize olive orchard husbandry and management in Andalusia. Each of the 65 olive orchards sampled was characterized for the presence and identity of $V$. dahliae VCG and pathotype, as well as the eight agricultural factors mentioned above. The dependent variables (occurrence of $V$. dahliae VCGs and pathotypes) were multinomial. For $V$. dahliae pathotypes, we denoted each component as follows: (i) D pathotype only present, (ii) ND pathotype only present, and (iii) both pathotypes present. Regarding VCGs, only VCG combinations having the highest frequencies (i.e., VCG1A, VCG2A, and their co-occurrence, VCG1A+VCG2A) were used for statistical analyses to avoid use of zero frequency. Consequently, we denoted each component as (i) VCG1A only present, (ii) VCG2A only present, and (iii) both VCG1A and VCG2A present.

Log-linear analyses. Log-linear models were used to analyze contingency tables (1). For the analyses, the agricultural factors listed above were categorized as follows: (i) irrigation management: irrigated and rain fed; (ii) source of irrigation water: well and river; (iii) source of planting stock: woody stems rooted by the farmer at the orchard and nursery-propagated self-rooted leafy stem cuttings; (iv) crop age (years old): $<10,10$ to $20,>20$ to 30 , and $>30$; (v) cropping history: virgin soil, cereals (e.g., maize, sorghum, and wheat), major $V$. dahliae-hosts in Andalusia (olive and cotton), other V. dahliae-host crops (e.g., faba bean, grape vine, potato, sugar beet, sunflower, tomato, and so on), and rotation of $V$. dahliae hosts with cereals; (vi) tree density (number of trees per hectare): low: <125, medium: 125 to 250 , high: $>250$ to 350 , and intensive: $>350$; (vii) soil texture: clay, sandy, clayloam, and sandy-loam; (viii) VW incidence: $<1,1$ to 4 , and $>4 \%$; (ix) latitude: 37.0 to $37.3^{\circ},>37.3$ to $37.6^{\circ},>37.6$ to $37.9^{\circ}$, and $>37.9^{\circ}$; and (x) longitude: -6.5 to $-5.5^{\circ},<-5.5$ to $-4.5^{\circ},<-4.5$ to $-3.5^{\circ}$, and $<-3.5^{\circ}$. The CATMOD procedure in SAS software (Statistical Analysis System, version 9.1; SAS Institute, Cary, NC) with a Poisson error and log link was used.

Multivariate analyses. Canonical discriminant (CD) analysis was used to assess the strength of the association among agricultural factors and $V$. dahliae groups; that is, (i) the three VCGs groups and (ii) the three pathotype groups in separate analyses. Only quantitative factors were included in the analysis (i.e., crop age, tree density, soil texture [expressed as clay, sand, and silt content], and geographic location). First, the STEPDISC procedure of SAS was used to eliminate variables within the model that do not provide additional information or were redundant as determined by the Wilks' lambda method, as well as to add variables outside the model that contribute most to the model (32). The DISCRIM procedure of SAS was then used to generate a discriminant function capable of determining the classification accuracy of the set of $V$. dahliae groups, based on the pooled covariance matrix and the prior probabilities of the classification groups. A training dataset of 65 olive orchards and a test dataset of 7 olive orchards, each consisting of three $V$. dahliae classes, were created for the STEPDISC selected model. The training set was used to train DISCRIM for classifying $V$. dahliae groups and the test dataset was used to evaluate the model classification accuracy. The data obtained from the stepwise analysis were further subjected to $\mathrm{CD}$ analysis using the CANDISC procedure of SAS to separate classification variables ( $V$. dahliae groups in this analysis) based on linear combinations of the quantitative variables (agricultural factors). The linear combinations of variables (canonical roots) were then correlated with the original groups. Canonical roots means (centroid values) were calculated for each classification variable and significance between means was determined using Mahalanobis distance (32). Individual values for each canonical root were plotted in a bi-plot for the first and second canonical variable.

\section{RESULTS}

Vegetative compatibility of $\boldsymbol{V}$. dahliae isolates. All $637 \mathrm{~V}$. dahliae isolates in the study produced nit mutants, with a total of 4,545 mutants. Of those nit mutants, $86.1 \%$ were classified as nit $1,11.9 \%$ as NitM, and $2 \%$ as nit3. All V. dahliae isolates except one produced nitl mutants but only $66 \%$ of the isolates produced NitM mutants and $12.2 \%$ formed nit 3 mutants. Positive complementation reactions of those mutants with nit mutants of the OARDC reference strains and Israeli tester strains allowed the assignment of the 131 initially tested isolates to VCG1A, -2A, $-2 \mathrm{~B}$, or $-4 \mathrm{~B}$. Thereafter, use of the local nit tester strains and of those specific testers enabled the assignment of the remaining 506 isolates to one of compatibility groups VCG1A, $-2 \mathrm{~A},-2 \mathrm{~B}$, or $-4 \mathrm{~B}$, except for 1 isolate that was heterokaryon self incompatible (HSI). Assignment of isolates to VCG using local tester strains was correlated with assignment made using OARDC and Israeli tester strains, with few exceptions. Thus, two isolates from Huelva province formed positive complementation with the OARDC reference and Israeli tester strains of VCG4B, as well as weak complementation with the local tester strain of VCG2A. Those two latter isolates were assigned to VCG4B. Also, the HSI isolate produced a positive complementation reaction with the local tester strain of VCG1A as well as with the OARDC reference strain of VCG1 and Israeli nit tester of VCG1A.

In all, the $637 \mathrm{~V}$. dahliae isolates from olive in Andalusia were assigned to VCGs as follows: 497 isolates $(78.1 \%)$ to VCG1A, $126(19.8 \%)$ to VCG2A, $4(0.6 \%)$ to VCG2B, and $9(1.4 \%)$ to VCG4Bl and 1 isolate was HSI (Table 2). A single VCG prevailed among isolates within an orchard but two VCGs were identified in $12(18.5 \%)$ orchards (VCG1A+VCG2A, 10 orchards; VCG2A+ VCG2B, 1 orchard; VCG2A+VCG4B, 1 orchard) and three VCGs in 3 orchards (VCG1A+VCG2A+VCG2B, 2 orchards; VCG1A+ VCG2A+VCG4B, 1 orchard). Also, in four trees from three

TABLE 2. Geographic distribution of vegetative compatibility groups (VCGs) of Verticillium dahliae from olive in Andalusia, southern Spain

\begin{tabular}{|c|c|c|c|c|c|c|}
\hline \multirow[b]{2}{*}{ Province } & \multicolumn{5}{|c|}{ Number of isolates } & \multirow[b]{2}{*}{ Total } \\
\hline & VCG1A $^{\mathrm{a}}$ & VCG2A & VCG2B & VCG4B & HSI & \\
\hline Córdoba & 141 & 21 & 0 & 0 & 0 & 162 \\
\hline Granada & 3 & 55 & 3 & 7 & 0 & 68 \\
\hline Jaén & 157 & 12 & 1 & 0 & 0 & 170 \\
\hline Sevilla & 160 & 6 & 0 & 0 & 1 & 167 \\
\hline Total & 497 & 126 & 4 & 9 & 1 & 637 \\
\hline
\end{tabular}

a Vegetative compatibility was determined using nitrate-nonutilizing mutants generated according to Korolev and Katan (33) and Correll et al. (17), and pairing them with complementary mutants of international Ohio Agricultural Research and Development Center reference and Israeli tester strains $(34,36,53)$. HSI = heterokaryon self-incompatible. 
orchards, the two isolates from a tree were of different VCGs: VCG1A+VCG2A (one tree from one of each orchards sampled at Córdoba, Granada, and Jaén provinces) and VCG2A+VCG2B (one tree from the same orchard at Granada as above). VCG1A and VCG2A occurred in the five provinces surveyed within the region and accounted for $54(83.1 \%)$ and $22(33.8 \%)$ orchards, respectively (Fig. 1; Table 2). Conversely, VCG2B and VCG4B were present in three and four orchards, respectively. Prevalence of the identified VCGs varied among provinces in the surveyed region. Isolates of VCG1A dominated the $V$. dahliae populations in olive orchards at Córdoba, Jaén, and Seville provinces: $87.0 \%$ of isolates in 20 of 21 orchards in Córdoba province, $92.3 \%$ of isolates in 15 of 16 orchards in Jaén province, and $95.8 \%$ of isolates in the 14 orchards surveyed in Seville province. The remaining isolates in those provinces were VCG2A (Córdoba, $13 \%$, one orchard; Jaén, $7.4 \%$, one orchard; Seville, $3.6 \%$, one orchard), except for one of the isolates from Jaén and another from Seville that were identified as VCG2B and HSI, respectively (Table 2). Isolates from Granada, in the southeastern part of the region, showed the highest VCG diversity; $80.9 \%$ of isolates belonged to the predominant VCG2A in 7 of 10 orchards, three isolates were of VCG1A in 2 orchards, another three were of VCG2B in 2 orchards, and seven isolates were of VCG4B in 3 orchards (Table 2). Isolates from Huelva, in the southwestern part of the region, were almost equally distributed between VCG1A (51.4\%) and VCG2A (45.7\%), each in three and two orchards, respectively; and two isolates $(2.9 \%)$ were of VCG4B in one orchard.

Molecular characterization of isolates by specific PCR and sequencing of the polymorphic $V$. dahliae-specific amplicon. All $V$. dahliae isolates yielded the species-specific 523- or 539-bp polymorphic DNA bands in PCR assays using the DB19/DB22 primer pair. All isolates of VCG1A and the single HSI isolate produced only the 334- and 462-bp amplicons diagnostic of the D pathotype when assayed using primers DB19/DB22/espdef01 or INTD2f/2r and INTND2f/2r, respectively. Consequently, these isolates were classified as D pathotype (Table 1; Fig. 1). Similarly, use of those primers for PCR assays of isolates assigned to VCG2A, -2B, and -4B yielded only the 824-bp amplicon diagnostic of ND $V$. dahliae (Table 1). Isolates of these latter VCGs were then classified as ND pathotype. The pathotype assigned to isolates correlated with the disease syndrome affecting sampled trees. Also, biological pathotyping of isolates on Picual olive plants further confirmed VCG1A/D isolates as defoliating and VCG2A, -2B, and $-4 \mathrm{~B} / \mathrm{ND}$ isolates as nondefoliating (data not shown) (24). Sequencing of the 523- or 539-bp amplicons from the $637 \mathrm{~V}$. dahliae isolates produced three (seq1, seq2, and seq4) of the seven seq sequences previously described $(13,14,16)$ (Table 1; Fig. 1). The sequences and VCGs of isolates were correlated as follows: seq1 was found only in isolates of VCG2B, seq2 was amplified from isolates of VCG2A and VCG4B, and seq4 occurred only in isolates of VCG1A and the single HSI isolate identified in the study (Table 1).

Association between $V$. dahliae VCGs and pathotypes from olive and variables that characterize olive orchard husbandry and management in Andalusia. Most of the agricultural factors

TABLE 4. Maximum likelihood analysis of variance from log-linear analyses for the effects of crop age and previous crop on the frequency of vegetative compatibility groups (VCG) of Verticillium dahliae (Vd) infecting olive in Andalusia, southern Spain

\begin{tabular}{|c|c|c|c|c|}
\hline Group & Source & df & $\chi^{2}$ & $P>\chi^{2 \mathrm{a}}$ \\
\hline \multicolumn{5}{|l|}{ Crop age } \\
\hline \multirow[t]{3}{*}{ Global } & $\operatorname{VCG}(\mathrm{A})$ & 2 & 29.69 & $<0.0001$ \\
\hline & Crop age (B) & 3 & 7.54 & 0.0566 \\
\hline & $\mathrm{A} \times \mathrm{B}$ & 6 & 16.08 & 0.0133 \\
\hline \multicolumn{5}{|l|}{ By crop age } \\
\hline$<10$ years old & VCG & 2 & 5.44 & 0.0660 \\
\hline $10-20$ years old & VCG $(1 \mathrm{~A}$ vs. $1 \mathrm{~A}+2 \mathrm{~A})$ & 1 & 1.82 & 0.1772 \\
\hline 20-30 years old & VCG & 1 & 1.03 & 0.5961 \\
\hline $\begin{array}{l}>30 \text { years old } \\
\text { by VCG }\end{array}$ & VCG (1A vs. 2A) & 1 & 8.83 & 0.0030 \\
\hline \multirow[t]{3}{*}{ VCG $1 \mathrm{~A}$} & Crop age & 3 & 10.85 & 0.0125 \\
\hline & Contrasts & & & \\
\hline & $>30$ vs. All others & 1 & 10.28 & 0.0013 \\
\hline VCG 2A & Crop age & 2 & 1.03 & 0.5961 \\
\hline VCG $1 \mathrm{~A}+2 \mathrm{~A}$ & Crop age & 2 & 0.20 & 0.9055 \\
\hline \multicolumn{5}{|l|}{ Cropping history ${ }^{\mathrm{b}}$} \\
\hline \multirow[t]{3}{*}{ Global } & $\operatorname{VCG}(\mathrm{A})$ & 2 & 29.69 & $<0.0001$ \\
\hline & Previous crop (B) & 4 & 10.59 & 0.0315 \\
\hline & $\mathrm{A} \times \mathrm{B}$ & 8 & 15.92 & 0.0435 \\
\hline \multicolumn{5}{|l|}{ By previous crop } \\
\hline None & VCG (1A vs. 2A) & 1 & 7.69 & 0.0056 \\
\hline Cereals & VCG $(1 \mathrm{~A}$ vs. $1 \mathrm{~A}+2 \mathrm{~A})$ & 1 & 1.51 & 0.2195 \\
\hline \multirow[t]{5}{*}{ Vd host crops } & VCG & 2 & 8.66 & 0.0132 \\
\hline & Contrasts & & & \\
\hline & $1 \mathrm{~A}$ vs. $2 \mathrm{~A}$ & 1 & 4.61 & 0.0317 \\
\hline & $1 \mathrm{~A}$ vs. $1 \mathrm{~A}+2 \mathrm{~A}$ & 1 & 5.50 & 0.0190 \\
\hline & $2 \mathrm{~A}$ vs. $1 \mathrm{~A}+2 \mathrm{~A}$ & 1 & 0.20 & 0.6569 \\
\hline Olive or cotton & VCG & 1 & 2.28 & 0.3203 \\
\hline $\begin{array}{l}\text { Rotation/cereal } \\
\text { by VCG }\end{array}$ & VCG & 2 & 0.48 & 0.7864 \\
\hline \multirow[t]{6}{*}{ VCG 1A } & Previous crop & 4 & 12.48 & 0.0141 \\
\hline & Contrasts & & & \\
\hline & None vs. all others & 1 & 10.51 & 0.0012 \\
\hline & $\begin{array}{l}\text { Cereals vs. (all Vd hosts, } \\
\text { rotation) }\end{array}$ & 1 & 0.23 & 0.6305 \\
\hline & All Vd hosts vs. rotation & 1 & 4.76 & 0.0291 \\
\hline & $\begin{array}{l}\text { Vd-hosts: Olive, cotton vs. } \\
\text { other suscp. vs. rotation }\end{array}$ & 1 & 0.13 & 0.7178 \\
\hline VCG 2A & Previous crop & 2 & 1.78 & 0.4097 \\
\hline $\mathrm{VCG} 1 \mathrm{~A}+2 \mathrm{~A}$ & Previous crop & 2 & 1.20 & 0.5479 \\
\hline
\end{tabular}

a Significant if $P<0.05$.

b Cropping history: None = virgin soil; Cereals = maize, sorghum, wheat, and so on; major $V$. dahliae host crops = olive and cotton; other susceptible (suscp.) V. dahliae host crops = faba bean, grape vine, potato, sugar beet, sunflower, tomato, and so on; and rotation of $V$. dahliae hosts with cereals.

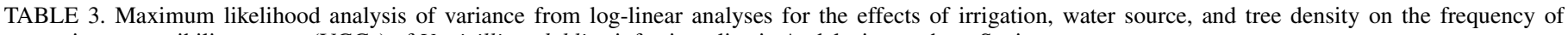
vegetative compatibility groups (VCGs) of Verticillium dahliae infecting olive in Andalusia, southern Spain

\begin{tabular}{|c|c|c|c|c|c|c|c|c|c|c|c|c|}
\hline \multirow[b]{2}{*}{ Source } & \multicolumn{3}{|c|}{ Irrigation management ${ }^{\mathrm{a}}$} & \multicolumn{3}{|c|}{ Source of irrigation water ${ }^{b}$} & \multicolumn{3}{|c|}{ Source of planting stock ${ }^{\mathrm{c}}$} & \multicolumn{3}{|c|}{ Tree density $^{\mathrm{d}}$} \\
\hline & df & $\chi^{2}$ & $P>\chi^{2 \mathrm{e}}$ & $\mathrm{df}$ & $\chi^{2}$ & $P>\chi^{2 \mathrm{e}}$ & df & $\chi^{2}$ & $P>\chi^{2 \mathrm{e}}$ & df & $\chi^{2}$ & $P>\chi^{2 \mathrm{e}}$ \\
\hline VCG (A) & 2 & 29.69 & $<0.0001$ & 2 & 20.06 & $<0.0001$ & 2 & 29.69 & $<0.0001$ & 2 & 29.69 & $<0.0001$ \\
\hline Factor (B) & 1 & 13.93 & 0.0002 & 1 & 18.70 & $<0.0001$ & 1 & 23.16 & $<0.0001$ & 3 & 6.03 & 0.1103 \\
\hline $\mathrm{A} \times \mathrm{B}$ & 2 & 6.86 & 0.0324 & 2 & 1.64 & 0.4397 & 2 & 2.56 & 0.2782 & 6 & 8.45 & 0.2069 \\
\hline Contrasts (by A & & & & & & & & & & & & \\
\hline $1 \mathrm{~A}$ vs. $2 \mathrm{~A}$ & 1 & 14.33 & 0.0002 & 1 & 14.33 & 0.0002 & 1 & 18.68 & $<0.0001$ & 1 & 18.10 & 0.0001 \\
\hline $1 \mathrm{~A}$ vs. $1 \mathrm{~A}+2 \mathrm{~A}$ & 1 & 9.05 & 0.0026 & 1 & 9.05 & 0.0026 & 1 & 16.01 & $<0.0001$ & 1 & 16.01 & $<0.0001$ \\
\hline $2 \mathrm{~A}$ vs. $1 \mathrm{~A}+2 \mathrm{~A}$ & 1 & 2.40 & 0.1214 & 1 & 2.40 & 0.1214 & 1 & 0.52 & 0.4692 & 1 & 0.52 & 0.4692 \\
\hline
\end{tabular}

a Irrigation management: irrigated and rain fed.

b Source of irrigation water: well and river.

c Source of planting stock: woody stems rooted by the farmer at the orchard and nursery-propagated self-rooted leafy stem cuttings.

d Tree density (number of trees per hectare): low: $<125$, medium: 125 to 250 , high: $>250$ to 350 , and intensive: $>350$.

e Significant if $P<0.05$. 
in the study were significantly associated with VCG frequency distribution, with the VCG1A/D pathotype being the most prevalent $(P<0.05)$ regardless of the factor analyzed. In addition, there were no significant differences $(P \geq 0.05)$ between prevalence of the VCG2A/ND pathotype and that of the co-occurrence of VCG1A+VCG2A (Tables 3 to 5).

The VCG1A/D pathotype was significantly more prevalent in irrigated orchards $\left(\chi^{2}=8.10, P=0.004\right)$ whereas VCG2A/ND pathotype was similarly prevalent $\left(\chi^{2}=0.14, P=0.706\right)$ in irrigated and nonirrigated ones (6.9 and $5.2 \%$, respectively). These two VCGs were jointly detected in irrigated orchards but not in nonirrigated ones. In irrigated orchards, both the VCG1A/D and VCG2A/ND pathotype, as well as the joint occurrence of VCG1A+VCG2A, were more prevalent $(P<0.001)$ when the irrigation water was from wells rather than from a river (Table 3; Fig. 2A). Similarly, those three VCG groupings were also more

TABLE 5. Maximum likelihood analysis of variance from log-linear analyses for the effects of soil texture, disease incidence, and geographic location (latitude and longitude) of olive orchards on the frequency of vegetative compatibility groups (VCGs) of Verticillium dahliae infecting olive in Andalusia, southern Spain

\begin{tabular}{|c|c|c|c|}
\hline Source & df & $\chi^{2}$ & $P>\chi^{2 \mathrm{a}}$ \\
\hline \multicolumn{4}{|l|}{ Soil texture ${ }^{b}$} \\
\hline VCG (A) & 2 & 29.69 & $<0.0001$ \\
\hline Soil texture (B) & 4 & 6.50 & 0.1648 \\
\hline$A \times B$ & 8 & 11.28 & 0.1708 \\
\hline \multicolumn{4}{|l|}{ Contrasts (A) } \\
\hline 1A vs. $2 \mathrm{~A}$ & 1 & 18.68 & $<0.0001$ \\
\hline $1 \mathrm{~A}$ vs. $1 \mathrm{~A}+2 \mathrm{~A}$ & 1 & 16.01 & $<0.0001$ \\
\hline $2 \mathrm{~A}$ vs. $1 \mathrm{~A}+2 \mathrm{~A}$ & 1 & 0.52 & 0.4692 \\
\hline \multicolumn{4}{|l|}{ Disease incidence ${ }^{c}$} \\
\hline $\operatorname{VCG}(\mathrm{A})$ & 2 & 26.32 & $<0.0001$ \\
\hline Soil texture (B) & 2 & 7.03 & 0.0298 \\
\hline $\mathrm{A} \times \mathrm{B}$ & 4 & 6.77 & 0.1484 \\
\hline \multicolumn{4}{|l|}{ Contrasts (A) } \\
\hline $1 \mathrm{~A}$ vs. $2 \mathrm{~A}$ & 1 & 16.92 & 0.0001 \\
\hline $1 \mathrm{~A}$ vs. $1 \mathrm{~A}+2 \mathrm{~A}$ & 1 & 14.11 & 0.0002 \\
\hline $2 \mathrm{~A}$ vs. $1 \mathrm{~A}+2 \mathrm{~A}$ & 1 & 0.52 & 0.4692 \\
\hline \multicolumn{4}{|l|}{ Contrasts (B) } \\
\hline Di 1 vs. Di 2,3 & 1 & 4.49 & 0.0341 \\
\hline Di 2 vs. 3 & 1 & 4.52 & 0.0334 \\
\hline \multicolumn{4}{|l|}{ Latitude $^{\mathrm{d}}$} \\
\hline VCG (A) & 2 & 26.77 & $<0.0001$ \\
\hline Latitude (B) & 3 & 9.70 & 0.0213 \\
\hline $\mathrm{A} \times \mathrm{B}$ & 6 & 1.56 & 0.9558 \\
\hline \multicolumn{4}{|l|}{ Contrasts (A) } \\
\hline $1 \mathrm{~A}$ vs. $2 \mathrm{~A}$ & 1 & 18.68 & $<0.0001$ \\
\hline $1 \mathrm{~A}$ vs. $1 \mathrm{~A}+2 \mathrm{~A}$ & 1 & 16.01 & $<0.0001$ \\
\hline $2 \mathrm{~A}$ vs. $1 \mathrm{~A}+2 \mathrm{~A}$ & 1 & 0.52 & 0.4692 \\
\hline \multicolumn{4}{|l|}{ Contrast (B) } \\
\hline Lt 1,2 vs. Lt 3,4 & 1 & 2.19 & 0.1390 \\
\hline Lt 1 vs. Lt 2 & 1 & 5.15 & 0.0233 \\
\hline Lt 3 vs. Lt 4 & 1 & 0.18 & 0.6702 \\
\hline \multicolumn{4}{|l|}{ Longitude $^{\mathrm{e}}$} \\
\hline VCG (A) & 2 & 26.68 & $<0.0001$ \\
\hline Longitude (B) & 3 & 12.98 & 0.0099 \\
\hline $\mathrm{A} \times \mathrm{B}$ & 6 & 5.35 & 0.4998 \\
\hline \multicolumn{4}{|l|}{ Contrasts (A) } \\
\hline $1 \mathrm{~A}$ vs. $2 \mathrm{~A}$ & 1 & 18.68 & $<0.0001$ \\
\hline $1 \mathrm{~A}$ vs. $1 \mathrm{~A}+2 \mathrm{~A}$ & 1 & 16.01 & $<0.0001$ \\
\hline $2 \mathrm{~A}$ vs. $1 \mathrm{~A}+2 \mathrm{~A}$ & 1 & 0.52 & 0.4692 \\
\hline \multicolumn{4}{|l|}{ Contrast (B) } \\
\hline $\operatorname{Lg} 1,2$ vs. $\operatorname{Lg} 3,4$ & 1 & 0.04 & 0.8360 \\
\hline $\operatorname{Lg} 1$ vs. $\operatorname{Lg} 2$ & 1 & 9.86 & 0.0017 \\
\hline $\operatorname{Lg} 3$ vs. $\operatorname{Lg} 4$ & 1 & 1.77 & 0.1830 \\
\hline
\end{tabular}

a Significant if $P<0.05$.

b Soil texture levels: St 1 = clay; St 2 = sandy; St 3 = loam; St 4 = clay-loam; and St 5 = sandy-loam.

c Disease incidence levels: Di 1, <1\%; Di 2, 1 to $4 \%$; Di 3, $>4 \%$.

${ }^{\mathrm{d}}$ Latitude levels (south to north, $1^{\circ} \approx 112 \mathrm{~km}$ ): Lt $1=37.0$ to $37.3^{\circ}$; Lt $2=$ 37.3 to $37.6^{\circ}$; Lt $3=37.6$ to $37.9^{\circ}$; Lt $4=>37.9^{\circ}$.

${ }^{\mathrm{e}}$ Longitude levels (west to east, $1^{\circ} \approx 90 \mathrm{~km}$ ): $\operatorname{Lg} 1=-6.5$ to $-5.5^{\circ} ; \operatorname{Lg} 2=$ -5.5 to $-4.5^{\circ} ; \operatorname{Lg} 3=-4.5$ to $-3.5^{\circ}$; and $\operatorname{Lg} 4=<-3.5^{\circ}$. prevalent $(P<0.05)$ in orchards established using woody stems rooted by the farmer than in those established with nurserypropagated planting stocks (Table 3; Fig. 2B).

Overall, crop age was not significantly associated with VCG frequency $\left(\chi^{2}=7.54, P=0.057\right)$ but there was a significant $\left(\chi^{2}=\right.$ $16.08, P=0.013)$ crop age-VCG interaction. VCG1A/D was most prevalent $\left(\chi^{2}=10.28, P=0.001\right)$ in older orchards $(>30$ years old) and occurred with moderate frequency in olive orchards with trees $<20$ years old (15.5 to $17.2 \%$ ), with the lowest frequency $(5.2 \%)$ occurring in orchards 20 to 30 years old (Table 4; Fig. 3C). That variation in frequency distribution associated with crop age did not occur for VCG2A/ND and the co-occurrence of VCG1A+VCG2A, which were present in $\approx 5 \%$ of orchards in most of the tree-age classes (Fig. 2C).

The cropping history of soil in an orchard was significantly associated with the prevalence of VCGs $\left(\chi^{2}=10.59, P=0.032\right)$ (Table 4). No significant differences $\left(\chi^{2}<1.51, P>0.219\right)$ existed among VCG groupings in orchards in which soil had previously been sown to cereals, or to cereals and $V$. dahliae hosts in rotation. Conversely, the VCG1A/D pathotype was significantly more prevalent $\left(\chi^{2}=11.15, P=0.011\right)$ than VCG2A/ND in orchards in which soil was previously uncropped (virgin soils) or cropped to $V$. dahliae-susceptible hosts (Fig. 2D). VGC frequencies in orchards previously cropped to cotton or olive were similar to those found in orchards previously cropped to other $V$. dahliae-susceptible hosts $\left(\chi^{2}<0.13, P=0.718\right)$. Fields potentially lacking a previous history of VW (i.e., virgin soils or fields previously cropped to cereals), which represented $48 \%$ of the surveyed orchards, harbored VCG1A/D. These fields had been established predominantly using woody stems rooted by the farmer $\left(\chi^{2}=10.10, P=0.002\right)$ in both irrigated and nonirrigated orchards $\left(\chi^{2}=3.33, P=0.068\right)$ (data not shown). Tree density in an olive orchard was not associated with the prevalence of VCGs in this study $\left(\chi^{2}=6.03, P=0.110\right)$. However, prevalence of VCG1A/D decreased with the increase in tree density, ranging from $31.0 \%$ at the lowest density $\left(<125\right.$ trees $\left.\mathrm{ha}^{-1}\right)$ to $6.9 \%$ at the highest $\left(>350\right.$ trees $\left.\mathrm{ha}^{-1}\right)$, with similar frequencies $(15.5$ and $17.2 \%$ ) occurring in orchards with tree density values in between the two tree density classes. No particular trend of variation with tree density was observed for the other two VCG groupings (Table 3; Fig. 2E).

Soil type in an orchard was not significantly associated with VCG distribution $\left(\chi^{2}=6.50, P=0.165\right)$. Overall, the three VCG groupings in the study were more prevalent in loam and clayloam soils compared with clay soil (Fig. 3F). In particular, it was remarkable that the prevalence of VCG1A/D was least in clay soil (7.3\%) compared with that in the other four soil types in the study for which prevalence was similar, 21.9 to $24.4 \%$ (Table 5; Fig. 2F).

Overall, disease incidence in the surveyed olive orchards averaged $3.45 \%$ ( 0.06 to $42.80 \%$ ). Disease incidence in orchards harboring the VCG1A/D pathotype averaged $2.66 \%(0.01$ to $33.30 \%$ ) and that in orchards harboring the VCG2A/ND pathotype averaged $9.03 \%$ ( 0.40 to $42.80 \%)$. Overall, disease incidence was significantly associated with the prevalence of VCGs $\left(\chi^{2}=\right.$ $7.03, P=0.030$ ) (Table 5). However, whereas prevalence of VCG1A/D tended to decrease with the increase in disease incidence, VCG2A/ND and the joint occurrence of VCG1A+VCG2A were most prevalent in orchards with a disease incidence of 1 to $4 \%$ (Fig. 2G).

The geographic location (latitude and longitude) of an orchard also was a significant factor $\left(\chi^{2}>9.70, P=0.021\right)$ in the distribution of the VCG groupings, but there was a similar effect across them; i.e., no significant interaction between orchard location and VCG frequency distribution $\left(\chi^{2}<5.35, P>0.500\right)$ (Table 5). VCG1A/D was widely distributed in the full range of latitude and longitude, but particularly at 37.3 to $37.6^{\circ}$ latitude that includes most of Jaén, Córdoba, and Seville provinces (Fig. 
$2 \mathrm{H}$ and $\mathrm{J}$ ). The VCG2A/ND-pathotype showed a narrower distribution at -4.5 to $-3.5^{\circ}$ longitude, which included mostly olive orchards located in Granada province in the southeastern part of the surveyed area (Fig. 2I and J). The co-occurrence of VCG1A and VCG2A in an orchard was detected at -3.5 to $-4.5^{\circ}$ longitude range across the full latitude range (Fig. $2 \mathrm{H}$ and $\mathrm{I}$ ).

Discriminant function and canonical analyses. The set of model variables selected in the step forward discriminant analysis is given in Table 6. In this model, agricultural factors that contributed most to discriminating among $V$. dahliae pathotypes categories were longitude, plant density, latitude, and crop age, and, to a lesser extent, soil texture (Table 6). Use of the linear discriminant function allowed classifying the sampled orchards in a given $V$. dahliae pathotype category. All orchards harboring the D pathotype were correctly classified in the D category, $72.7 \%$ of orchards harboring the ND pathotype were in the ND category, and the co-occurrence of both pathotypes in an orchard was predicted with less accuracy $(38.5 \%)$. Overall, the achieved classification accuracy of the model was $83.1 \%$. Of the three misclassified ND orchards, two were categorized into the D and one in the D+ND category. Similarly, of the eight orchards harboring $\mathrm{D}+\mathrm{ND}$, seven were categorized into the $\mathrm{D}$ and one in the ND category. The degree to which these three categories are separated is measured by Mahalanobis distance between centroid values for each pathotype category (Table 7). As expected, all pairwise distances between the three pathotype categories were statistically significant $(P \leq 0.004)$, except for the distance between the D and D+ND pathotype categories $(P=0.052)$ (Table 7$)$. The predicted accuracy of the discriminant model was assessed using a cross- validation sample of 10 unknown olive orchards not included in the original data set. Blind tests using olive tissues sampled from affected trees in those orchards typed the infecting pathotype to $\mathrm{D}$ in nine orchards and ND in one orchard. The model correctly

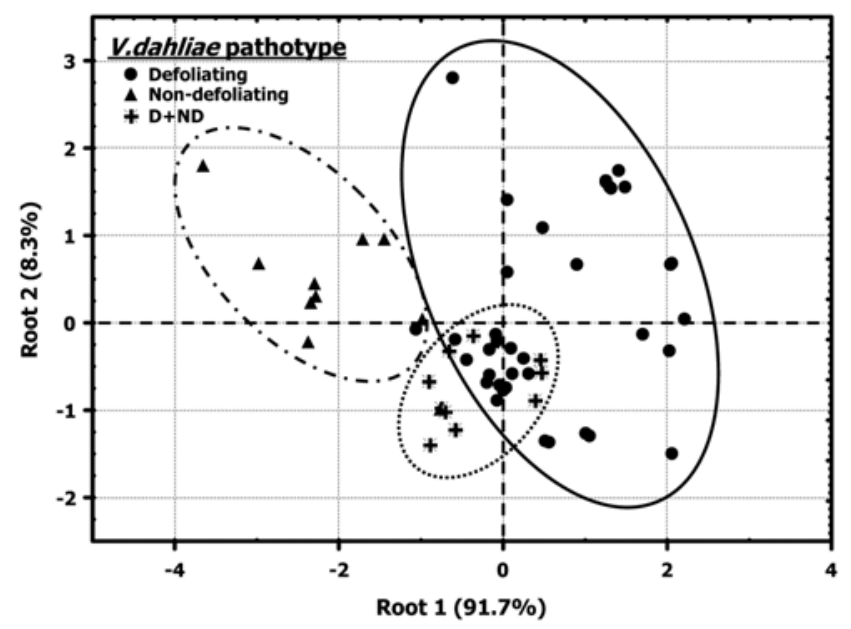

Fig. 3. Classification of 65 olive orchards in Andalusia, southern Spain into three Verticillium dahliae pathotype categories based on the first and second canonical functions, from the canonical discriminant analysis. Stepwise multiple discriminant and canonical discriminant analyses identified tree density, crop age, and geographic location of olive orchards (longitude and latitude) as contributing the most to separating the three $V$. dahliae pathotype categories. $\mathrm{D}=$ defoliating and $\mathrm{ND}=$ nondefoliating pathotypes.
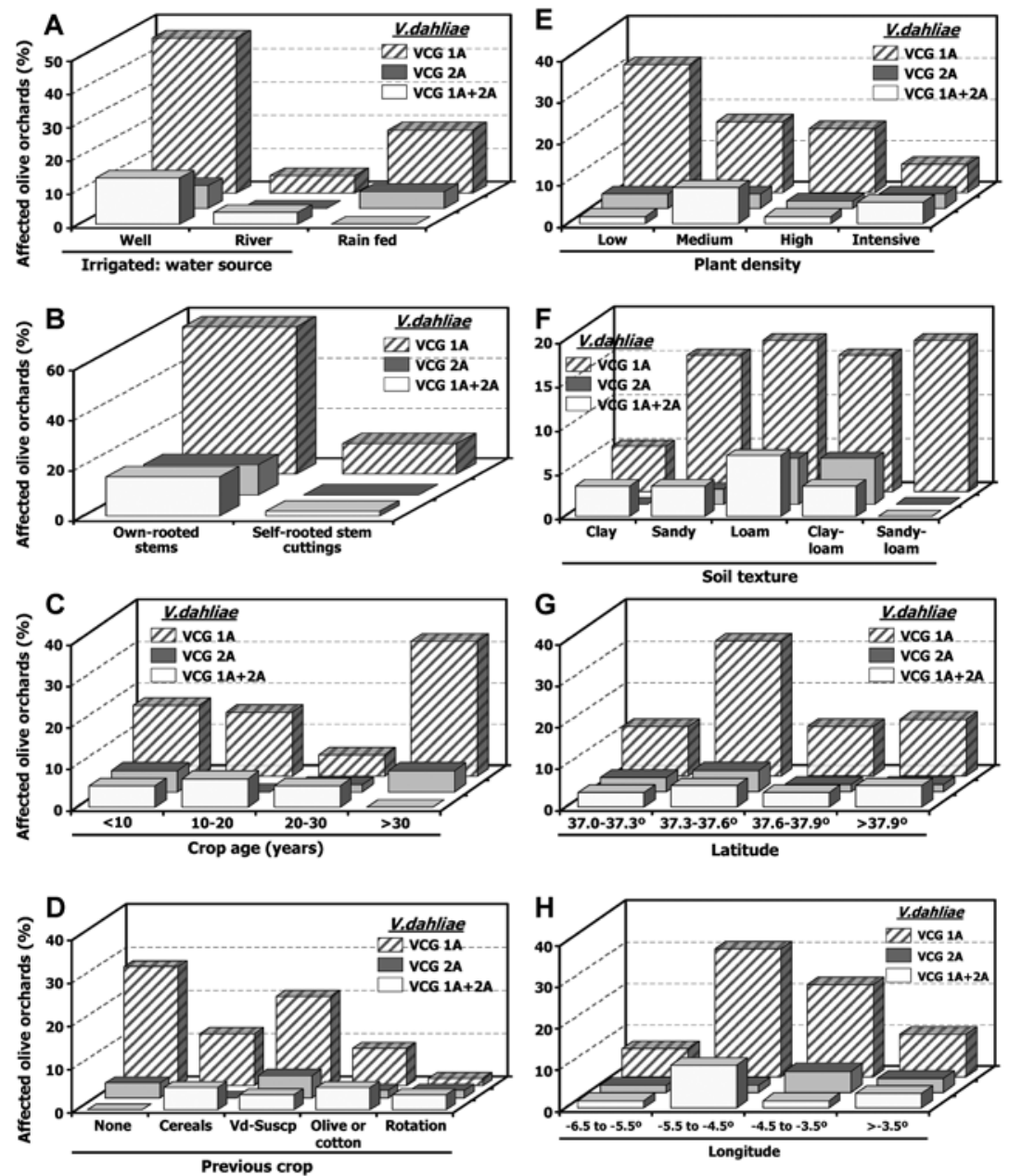

Fig. 2. Prevalence of Verticillium dahliae Vegetative Compatibility Groups (VCG) in 65 olive orchards in Andalusia, southern Spain according to A, source of irrigation water; B, source of planting stock; $\mathbf{C}$, crop age; D, history of previous crops; $\mathbf{E}$, plant density; $\mathbf{F}$, soil texture; $\mathbf{G}$, latitude; and $\mathbf{H}$, longitude. 
identified the $V$. dahliae pathotype in all cases, thus demonstrating its usefulness.

Agricultural factors included in the discriminant model were then used in a $\mathrm{CD}$ analysis. In this analysis, two canonical functions (roots) were derived. The first canonical root accounted for $91.7 \%$ of the variation and was dominated by positive loadings from crop age and latitude and negative loadings from longitude and plant density. The second canonical root, accounting for the remaining $8.3 \%$ of the variation, was dominated by positive loadings from crop age, plant density, and longitude and negative loading from latitude (Table 8). According to canonical loadings, the D pathotype occurred in the full range of crop age and latitude but at moderate to low tree density and low longitude (southwestern part of the surveyed area). In contrast, the ND pathotype occurred preferentially in older orchards, high longitude and low latitude (southeastern part of the surveyed area), and high tree density. CD analysis segregated orchards harboring the $\mathrm{D}$ pathotype from those harboring the ND one. Orchards harboring D+ND jointly were located close to orchards with the D pathotype (Fig. 3).

\section{DISCUSSION}

Genetic and virulence characterization of prevailing $V$. dahliae populations infecting olive in a region are key elements for the efficient management of VW through disease prediction and use of host resistance. In this study, VCG typing, molecular pathotyping, and sequence analysis of a $V$. dahliae-specific PCR marker of a large number of $V$. dahliae isolates indicated that little genetic and virulence diversity exist within $V$. dahliae populations infecting olive in Andalusia, which are dominated by the VCG1A/D pathotype. Also, log-linear analyses indentified agricultural factors that were significantly associated with the prevalence of VCGs and pathotypes, some of which (e.g., source of irrigation water and planting stocks) may potentially have contributed to dispersal of VCG1A/D across the region. Moreover, multivariate analyses using a selected set of those factors as variables allowed us to develop a discriminant model for predicting the occurrence of D and ND pathotypes in the area of the study. This is the first time that frequency distribution of genetically and virulence-characterized populations of $V$. dahliae from olive in a region were related to factors involved in crop husbandry and management. A similar statistical approach was used to assess the strength of association of soil variables within Pythium communities collected from agronomic production fields in Ohio (8).

Although there were four VCGs identified among the $637 \mathrm{~V}$. dahliae isolates in the study, only two of them, VCG1A and VCG2A, accounted for 78.1 and $19.8 \%$ of isolates, respectively. These two VCGs occurred singly in an orchard in most cases but, in 13 orchards, in association with either VCG2B or VCG4B. Therefore, the overall prevalence of VCG1A and VCG2A reached 83.1 and $33.8 \%$ of the 65 surveyed orchards, respectively. Conversely, VCG2B and VCG4B accounted for the remaining $2 \%$ of isolates in three and four orchards, respectively. This limited VCG diversity and predominance of VCG1A among $V$. dahliae infecting olive in southern Spain suggest a clonal structure of the pathogen population within the region. Interestingly, a similar predominance of VCG1A and limited VCG diversity was reported for olive V. dahliae in Turkey, where VCG2A and VCG4B were found to be minor components of the pathogen population $(19,20)$. Studies in other olive-growing countries in the Mediterranean Basin reported VCG2 and VCG4B as predominant groups in Greece (22) and Morocco (12), and VCG2B and VCG4B in Israel (61). Typing of individual $V$. dahliae isolates also indicated the occurrence of VCG2A in olive in Cyprus, Italy, and Syria (15). The limited $V$. dahliae VCG diversity associated with a crop in an area, which has been reported in several crops and regions $(7,21,29,34,35,56,57)$, may reflect the cropping history of $V$. dahliae-susceptible plants in soils and is consistent with the perception of $V$. dahliae isolates being primarily host adapted $(6,25,50)$. Interestingly, the described scenarios concerning VCG1A/D pathotype in Andalusia and Turkey are coincident in that the olive crops in the two countries are expanding to occupy soils previously cropped to cotton, which is as susceptible to VCG1A/D as olive $(3,19,20,35,45,52,55)$.

Assignment of isolates to VCGs with the international reference strains and local tester strains was fully correlated but two VCG4B isolates formed weak complementation with the local tester strain of VCG2A. Such weak heterologous complementation reaction between VCG2A and VCG4B isolates has also been observed to occasionally occur with $V$. dahliae from potato $(6,28,57)$ and it seems to correlate with a degree of molecular similarity and phylogenetic relatedness between those VCGs $(6,14,15)$.

The limited genetic variability in $V$. dahliae populations infecting olive in Andalusia indicated by little VCG diversity is reinforced by the patterns of PCR markers amplified from them in single- and duplex-PCR assays using specific primers, as well as by the type of seq sequence of a $V$. dahliae-specific amplicon. All VCG1A isolates produced the 462-bp marker of the D pathotype and seq4 sequence characteristic of VCG1A, as well as the

TABLE 7. Squared Mahalanobis distances for Verticillium dahliae pathotypes categories infecting olive in Andalusia, southern Spain obtained in a stepwise discriminant analysis

\begin{tabular}{lccccc}
\hline & \multicolumn{2}{c}{$\begin{array}{c}\text { Squared Mahalanobis } \\
\text { distance }\end{array}$} & & \multicolumn{2}{c}{$F$ values $(P)$} \\
\cline { 2 - 3 } \cline { 5 - 6 } Pathotype category & $\mathrm{ND}$ & $\mathrm{D}+\mathrm{ND}$ & & $\mathrm{ND}$ & $\mathrm{D}+\mathrm{ND}$ \\
\hline Defoliating (D) & 5.7570 & 1.0643 & & $\begin{array}{c}11.8787 \\
(<0.0001)\end{array}$ & $\begin{array}{c}2.4992 \\
(0.0521)\end{array}$ \\
Nondefoliating (ND) & $\ldots$ & 3.0574 & & $\ldots$ & $\begin{array}{c}4.3339 \\
\end{array}$ \\
& & & & & $(0.0039)$ \\
\hline
\end{tabular}

TABLE 8. Standardized canonical coefficients (SCCs) and correlation coefficients (CCC) of discriminant canonical functions of agronomic factors that determine the distribution of pathotypes of Verticillium dahliae infecting olive in Andalucía, southern Spain, selected by a stepwise discriminant analysis

\begin{tabular}{lrrrrr}
\hline \multirow{2}{*}{ Source } & \multicolumn{2}{c}{ SSCs } & & \multicolumn{2}{c}{ CCCs } \\
\cline { 2 - 3 } \cline { 5 - 6 } & Root 1 & Root 2 & & Root 1 & Root 2 \\
\hline Crop age & 0.515 & 0.926 & & 0.337 & 0.839 \\
Longitude & -1.353 & 0.290 & & -0.245 & 0.138 \\
Plant density & -0.872 & 0.221 & & -0.318 & 0.020 \\
Latitude & 0.839 & -0.657 & & 0.259 & -0.272 \\
Eigenvalue & 0.819 & 0.074 & & $\ldots$ & $\ldots$ \\
Cumulative proportion & 0.917 & 0.083 & & $\ldots$ & $\ldots$ \\
\hline
\end{tabular}

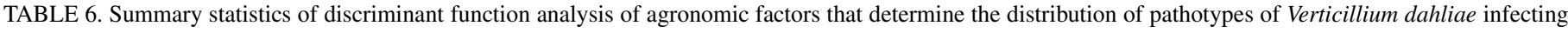
olive in Andalusia, southern Spain

\begin{tabular}{|c|c|c|c|c|c|c|}
\hline Source & Wilks' lambda & Partial lambda & $F$ remove & $P$ level & Tolerance & 1 Tolerance \\
\hline Longitude & 0.7921 & 0.6460 & 16.1635 & $<0.0001$ & 0.4261 & 0.5739 \\
\hline Plant density & 0.6687 & 0.7653 & 9.0467 & 0.0004 & 0.6786 & 0.3214 \\
\hline Latitude & 0.6486 & 0.7889 & 7.8935 & 0.0009 & 0.6085 & 0.3915 \\
\hline Crop age & 0.6046 & 0.8463 & 5.3557 & 0.0073 & 0.8607 & 0.1393 \\
\hline
\end{tabular}


334-bp amplicon that is present in D isolates and some ND isolates of VCG1B and VCG2B $(14-16,25,43)$. Conversely, all isolates in VCG2A, -2B, and -4B produced the 824-bp marker of ND $V$. dahliae and sequences seq 1 or seq 2 depending upon VCGs (14). The 462- and 824-bp markers, and the 334-bp one, were developed from a random amplified polymorphic DNA amplicon polymorphic in D and ND isolates and a speciesspecific amplicon produced by primers derived from a $V$. dahliae genomic library, respectively (10,43-45). These markers are unlikely to be linked to a virulence gene but their association with the D or ND phenotypes has been consistently demonstrated in many studies and by different laboratories $(15,16,20,24,25$, $36,40,46)$. The correlation found between molecular and biological pathotyping of $\mathrm{D}$ and ND isolates in this present study is consistent with that association.

Previous studies indicated that $V$. dahliae VCG1A/D isolates from cotton and olive are molecularly heterogeneous; isolates from China and Spain harbor the 334- and 462-bp DNA fragments (namely, PCR pattern A) but VCG1A/D isolates from Greece, Israel, and Turkey only carry the 334-bp fragment (namely, PCR pattern B) $(15,36)$. Interestingly, all VCG1A isolates from olive in Turkey failed to amplify the 462-bp marker but did with the 334-bp fragment and caused defoliation in cotton and olive $(19,20)$. Because all olive VCG1A isolates from Andalusia yielded PCR pattern A, it appears that the VCG1A/D pathotype infecting olive comprises at least two distinct populations: one associated with PCR pattern A, located in Spain and perhaps other regions; and another yielding PCR pattern $\mathrm{B}$, existing in the Eastern Mediterranean Basin. The VCG1A/D pathotype is considered indigenous to the southern United States and northern Mexico $(5,42)$. However, VCG1A/D isolates of putative endemic origin were obtained from cotton and cotton soil in Iran and Tadjikistan $(18,23,49)$. Further demonstration of molecular diversity between patterns A and B in VCG1A/D might support earlier suggestions that new strains of VCG1A can develop independently in different geographic areas $(15,20)$.

The VCG1A/D pathotype that now dominates populations of $V$. dahliae infecting olive in Andalusia was first found to be restricted within well-defined zones of an intensively grown cotton marsh area in the Seville province in the southwestern part of that region in 1981 (3). Since then, new infections by this pathotype were reported in cotton and olive crops in a northeastern geographical pattern $(4,43)$ (R. M. Jiménez-Díaz, unpublished data). The regional distribution and prevalence of the VCG1A/D pathotype infecting olive in Andalusia may reflect factors influencing migration of the $\mathrm{D}$ pathotype from the location where it was first found. During the last 15 years, intensive olive cultivation (i.e., new, high-tree-density plantings; drip irrigation; and so on) has significantly expanded in Córdoba and Jaén provinces, which now account for $60 \%$ of the $1.5 \times 10^{6}$ ha of the crop in Andalusia. Correspondingly, the VCG1A/D pathotype in Seville, Jaén, and Córdoba provinces accounted for 95.8 to $87 \%$ of the total number of isolates in those provinces, respectively. A recent, putative migration and spread of VCG1A/D into those provinces might explain why the increased prevalence of this VCG did not correlate with an increase in incidence (i.e., the time elapsed from first introductions was not enough for subsequent dispersal and completion of disease cycles within orchards) (46).

Irrigation may have contributed to long-distance spread of the D pathotype across the olive-growing area in Andalusia. Loglinear analyses of associations between VCG prevalence and agricultural factors indicated that VCG1A/D was significantly more prevalent in irrigated compared with nonirrigated orchards, and in orchards irrigated with water from wells compared with those irrigated with water from rivers. In a recent study, large numbers of $V$. dahliae propagules were found in water sampled from irrigation drips in VW-affected trees in 18 of 21 orchards in Jaén and Sevilla provinces. Irrigation water was from wells or from ponds storing river water in 14 and 4 orchards, respectively (51).

The spread of the VCG1A/D pathotype in olive across the region also may have been enhanced by use of infected planting stocks for the establishment of new orchards. For that purpose, farmers use either wooden stems rooted in farm soil or self-rooted planting stocks purchased from nurseries. In 2006 and 2007, in planta molecular detection assays by the Plant Health Service of Andalusia indicated that $5.5 \%$ of $>600$ registered nurseries had $V$. dahliae-infected but symptomless olive planting stocks (P. Holgado, personal communication). Production of planting stocks in those registered olive nurseries satisfies official requirements by the European Union that do not enforce $V$. dahliae-free certification of those stocks. $V$. dahliae may also be spread in the potting soil used for nursery production, in addition to infected plants (47). In Andalusia, on-farm rooting of woody stems by farmers can contribute to spreading $V$. dahliae in infested root balls of planting stocks by inadvertently rooting them in areas with a long history of cotton presumably infested by the pathogen. This is further supported by our finding that orchards potentially lacking a history of VW-susceptible crops, representing $48 \%$ of the surveyed orchards, were found harboring the VCG1A/D pathotype, which may have been established using woody stems rooted by farmers.

VW of olive is best managed by combining the use of preventive control measures such as (i) choice of planting date and risk prediction; (ii) use of resistant cultivars, and (iii) use of pathogen-free planting material, and so on (60), the efficiency of which would enhance expression of the infected plant's ability to show remission from symptoms $(27,37,63)$. The widespread occurrence and high prevalence of the VCG1A/D pathotype in Andalusia compromise the efficiency of those control measures and, thus, have strong implications for the management of the disease because (i) VCG1A/D is more virulent than VCG2A, VCG2B, and VCG4B/ND isolates to olive cultivars $(20,40,44,45)$; (ii) the threshold of inoculum density for disease of $\mathrm{D}$ isolates is much lower compared with that of ND isolates (39); (iii) olive cultivars of commercial interest and resistant to the ND pathotype are highly to moderately susceptible to the D pathotype (40); and (iv) the ability of olive cultivars to recover from disease caused by the D pathotype is lessened compared with that from disease caused by the ND pathotype (38). Moreover, infected leaves dropping in large amounts from D-infected olive trees are efficient means of dispersal of the pathogen within and possibly among orchards, and a source of inoculum for secondary infections that determine a significant change in the epidemiology of VW in olive (46). In summary, infections by the VCG1A/D pathotype should now be the main target in the management of VW of olive in Andalusia. To that aim, new control measures are needed, such as resistant cultivars and rootstocks, pathogen-free planting stocks, and protection of the root system of healthy or recovered trees from secondary infections by the VCG1A/D pathotype. Use of the developed discriminant model for predicting the occurrence of $\mathrm{D}$ and ND pathotypes in an area may help in avoiding high risk soils for new plantings. Avoidance of soils already infested with VCG1A/D would be further facilitated if new, DNA-based methods are developed that overcome limitations of plating soil on semiselective media, for the sensitive and reliable quantification of this strain of the pathogen in soil.

\section{ACKNOWLEDGMENTS}

This research was supported by grant "Verticilosis del olivo" from Fundación Ramón Areces of Spain. We thank J. Katan, T. Paulitz, and K. Sivasithamparam for critically reading the manuscript and making valuable suggestions prior to submission; R. C. Rowe and T. Katan for providing reference strains of $V$. dahliae VCGs and Israeli nit testers, respectively; J. L. Trapero-Casas for technical support; the late M. Pastor, 
who greatly helped with carrying out the olive surveys; and anonymous reviewers and the Senior Editor for editorial improvement of the manuscript.

\section{LITERATURE CITED}

1. Agresti, A. 2002. Categorical Data Analysis, 2nd ed. Wiley, New York.

2. Atallah, Z. A., Maruthachalam, K., du Toit, L., Koike, S. T., Davis, M. R., Klosterman, S. J., Hayes, R. J., and Subbarao, K. V. 2010. Population analyses of the vascular plant pathogen Verticillium dahliae detect recombination and transcontinental gene flow. Fungal Genet. Biol. 47:416-422.

3. Bejarano-Alcázar, J. Blanco-López, M. A., Melero-Vara, J. M., and Jiménez-Díaz, R. M. 1996. Etiology, importance, and distribution of Verticillium wilt of cotton in southern Spain. Plant Dis. 80:1233-1238.

4. Bejarano-Alcázar, J. Pérez-Artés, E., and Jiménez-Díaz, R. M. 2001. Spread of the defoliating pathotype of Verticillium dahliae to new cottonand olive-growing areas in southern Spain. Page 57 in: Abstr. 8th Int. Verticillium Symp. Córdoba, Spain.

5. Bell, A. A. 1994. Mechanisms of disease resistance in Gossypium species and variation in Verticillium dahliae. Pages 225-235 in: Proc. World Cotton Res. Conf. G. A. Constable and N. W Forrester, eds. CSIRO, Melbourne, Australia.

6. Berbegal, M., Ortega, A., Jiménez-Gasco, M. M., Olivares-García, C., Jiménez-Díaz, R. M., and Armengol, J. 2010. Genetic diversity and host range of Verticillium dahliae isolates from artichoke and other vegetable crops in Spain. Plant Dis. 94:396-404.

7. Bhat, R. G., Smith, R. F., Koike, S. T., Wu, B. M., and Subbarao, K. V. 2003. Characterization of Verticillium dahliae isolates and wilt epidemics of pepper. Plant Dis. 87:789-797.

8. Broders, K. D., Wallhead, M. W., Austin, G. D., Lipps, P. E., Paul, P. A., Mullen, R. W., and Dorrance, A. E. 2009. Association of soil chemical and physical properties with Pythium species diversity, community composition, and disease incidence. Phytopathology 99:957-967.

9. Caballero, J. M., Pérez Hernández, J., Blanco López, M. A., and Jiménez Díaz, R. M. 1980. Olive, a new host of Verticillium dahliae in Spain. Page 50 in: Proc. 5th Congr. Mediterr. Phytopathol. Union. Patras, Greece.

10. Carder, J. H., Morton, A., Tabrett, A. M., and Barbara, D. J. 1994. Detection and differentiation by PCR of subspecific groups within two Verticillium species causing vascular wilts in herbaceous hosts. Pages 9197 in: Modern Assays for Plant Pathogenic Fungi. A. Schots, F. M. Dewey, and R. Oliver, eds. CAB International, Wallingford, UK.

11. Chen, W. 1994. Vegetative compatibility groups of Verticillium dahliae from ornamental woody plants. Phytopathology 84:214-219.

12. Cherrab, M. Bennani, A., Charets, P. M., and Serrhini, N. N. 2002. Pathogenicity and vegetative compatibility of Verticillium dahliae Kleb from olive in Morocco. J. Phytopathol. 150:703-709.

13. Collado-Romero, M., Jiménez-Díaz, R. M., and Mercado-Blanco, J. 2010. DNA sequence analysis of conserved genes reveals hybridization events that increase genetic diversity in Verticillium dahliae. Fungal Biol. 114:209-218

14. Collado-Romero, M., Mercado-Blanco, J., Olivares-García, C., and Jiménez-Díaz, R. M. 2008. Phylogenetic analysis of Verticillium dahliae vegetative compatibility groups. Phytopathology 98:1019-1028.

15. Collado-Romero, M., Mercado-Blanco, J., Olivares-García, C., ValverdeCorredor, A., and Jiménez-Díaz, R. M. 2006. Molecular variability within and among Verticillium dahliae vegetative compatibility groups determined by fluorescent amplified fragment length polymorphism and polymerase chain reaction markers. Phytopathology 96:485-495.

16. Collins, A., Mercado-Blanco, J., Jiménez-Díaz, R. M., Olivares, C., Clewes, E., and Barbara, D.J. 2005. Correlation of molecular markers and biological properties in Verticillium dahliae and the possible origins of some isolates. Plant Pathol. 54:549-557.

17. Correll, J.C., Klittich, C. J. R., and Leslie, J. F. 1987. Nitrate nonutilizing mutants of Fusarium oxysporum and their use in vegetative compatibility tests. Phytopathology 77:1640-1646.

18. Daayf, F., Nicole, M., and Geiger, J. P. 1995. Differentiation of Verticillium dahliae populations on the basis of vegetative compatibility and pathogenicity on cotton. Eur. J. Plant Pathol. 101:69-79.

19. Dervis, S., Erten, L., Soylu, S., Tok, F. M., Kurt, S., Yildiz, M., and Soylu, E. M. 2007. Vegetative compatibility groups in Verticillium dahliae isolates from olive in Turkey. Eur. J. Plant Pathol. 119:437-447.

20. Dervis, S., Mercado-Blanco, J., Erten, L., Valverde-Corredor, A., and Pérez-Artés, E. 2010. Verticillium wilt of olive in Turkey: a disease survey on diseases importance, pathogen diversity and susceptibility of relevant olive cultivars. Eur. J. Plant Pathol. 127:287-301.

21. Elena, K. 2000. Vegetative compatibility among Verticillium dahliae isolates from watermelon in Greece. Phytoparasitica 28:115-120.

22. Elena, K., and Paplomatas, E. J. 1998. Vegetative compatibility groups within Verticillium dahliae isolates from different hosts in Greece. Plant Pathol. 47:635-640.

23. Hamdolla-Zadeh, A. 1993. Properties of defoliant and non-defoliant strains of Verticillium dahliae the causal agent of cotton wilt in northern Iran. Iran. J. Plant Pathol. 29:53-54.

24. Jiménez-Díaz, R. M. 2008. Final report of research project "Verticillium wilt of olive: development of key elements for management of the disease by means of resistant rootstocks", submitted to granting agency Fundación Ramón Areces, Madrid, Spain. (In Spanish)

25. Jiménez-Díaz, R. M., Mercado-Blanco, J., Olivares-García, C., ColladoRomero, M., Bejarano-Alcázar, J., Rodríguez-Jurado, D., Giménez-Jaime, A., García-Jiménez, J., and Armengol, J. 2006. Genetic and virulence diversity in Verticillium dahliae populations infecting artichoke in eastern-central Spain. Phytopathology 96:288-298.

26. Jiménez-Díaz, R. M., Olivares-García, C., Navas-Cortés, J. A., Landa, B. B., and Jiménez-Gasco, M. M. 2008. A region-wide analysis of genetic diversity in Verticillium dahliae infecting olive in Andalusia, southern Spain. (Abstr.) Phytopathology 98:S75.

27. Jiménez-Díaz, R. M., Tjamos, E. C., and Cirulli, M. 1998. Verticillium wilt of major tree hosts: Olive. Pages 13-16 in: A Compendium of Verticillium Wilt in Tree Species. J. A. Hiemstra, and D. C. Harris, eds. Ponsen and Looijen, Wageningen, The Netherlands.

28. Joaquim, T. R., and Rowe, R. C. 1990. Reassessment of vegetative compatibility relationships among strains of Verticillium dahliae using nitrate-nonutilizing mutants. Phytopathology 80:1160-1166.

29. Joaquim, T. R., and Rowe, R. C. 1991. Vegetative compatibility and virulence strains of Verticillium dahliae from soil and potato plant. Phytopathology 81:552-558.

30. Johnson, D. A., and Santo, G. S. 2001. Development of wilt in mint in response to infection by two pathotypes of Verticillium dahliae and coinfection by Pratylenchus penetrans. Plant Dis. 85:1189-1192.

31. Katan, T. 2000. Vegetative compatibility in populations of Verticilliuman overview. Pages 69-86 in: Advances in Verticillium Research and Disease Management. E. C. Tjamos, R. C. Rowe, J. B. Heale, and R. D. Fravel, eds. American Phytopathological Society Press, St. Paul, MN.

32. Khattree, R., and Naik, D. N. 2000. Multivariate Data Reduction and Discrimination with SAS Software. SAS Institute Inc., Cary, NC.

33. Korolev, N., and Katan, T. 1997. Improved medium for selecting nitrate nonutilizing (nit) mutants of Verticillium dahliae. Phytopathology 87:1067-1070.

34. Korolev, N., Katan, J., and Katan, T. 2000. Vegetative compatibility groups of Verticillium dahliae in Israel: their distribution and association with pathogenicity. Phytopathology 90:529-536.

35. Korolev, N., Pérez-Artés, E., Bejarano-Alcázar, J., Rodríguez-Jurado, D., Katan, J., Katan, T., and Jiménez-Díaz, R. M. 2001. Comparative study of genetic diversity and pathogenicity among populations of Verticillium dahliae from cotton in Spain and Israel. Eur. J. Plant Pathol. 107:443-456.

36. Korolev, N., Pérez-Artés, E., Mercado-Blanco, J., Bejarano-Alcázar, J., Rodríguez-Jurado, D., Jiménez-Díaz, R. M., Katan, T., and Katan, J. 2008. Vegetative compatibility of cotton-defoliating Verticillium dahliae in Israel and its pathogenicity to various crop plants. Eur. J. Plant Pathol. 122:603-617.

37. Levin, A. G., Lavee, S., and Tsror (Lahkim), L. 2003. Epidemiology of Verticillium dahliae on olive (cv. Picual) and its effects on yield under saline conditions. Plant Pathol. 52:212-218.

38. López-Escudero, F. J., and Blanco-López, M. A. 2005. Recovery of young olive trees from Verticillium dahliae. Eur. J. Plant Pathol. 113:365-375

39. López-Escudero, F. J., and Blanco-López, M. A. 2007. Relationship between the inoculum density of Verticillium dahliae and the progress of Verticillium wilt of olive. Plant Dis. 91:1372-1378.

40. López-Escudero, F. J., del Río, C., Caballero, J. M., and Blanco-López, M. A. 2004. Evaluation of olive cultivars for resistance to Verticillium dahliae. Eur. J. Plant Pathol. 110:79-85.

41. M.A.P.A. 2006. Encuesta sobre superficie y rendimiento de cultivos. Ministerio de Agricultura, Pesca y Alimentación, Madrid.

42. Mathre, D., Edwin, D. C., Paulus, A. O., and Ravenscroft, A. V. 1966. Comparison of the virulence of isolates of Verticillium albo-atrum from several of the cotton-growing regions in the United Stated, Mexico and Peru. Plant Dis. Rep. 50:930-933.

43. Mercado-Blanco, J., Rodríguez-Jurado, D., Parrilla-Araujo, S., and Jiménez-Díaz, R. M. 2003. Simultaneous detection of the defoliating and nondefoliating Verticillium dahliae pathotypes in infected olive plants by duplex, nested polymerase chain reaction. Plant Dis. 87:1487-1494.

44. Mercado-Blanco, J., Rodríguez-Jurado, D., Pérez-Artés, E., and JiménezDíaz, R. M. 2001. Detection of the nondefoliating pathotype of Verticillium dahliae in infected olive plants by nested PCR. Plant Pathol. 50:609-619.

45. Mercado-Blanco, J., Rodríguez-Jurado, D., Pérez-Artés, E., and JiménezDíaz, R. M. 2002. Detection of the defoliating pathotype of Verticillium dahliae in infected olive plants by nested PCR. Eur. J. Plant Pathol. 108:1-13. 
46. Navas-Cortés, J. A., Landa, B. B., Mercado-Blanco, J., Trapero-Casas, J. L., Rodríguez-Jurado, D., and Jiménez-Díaz, R, M. 2008. Spatiotemporal analysis of spread of Verticillium dahliae pathotypes within a high tree density olive orchard in southern Spain. Phytopathology 98:167-180.

47. Nigro, F., Gallone, P., Romanazzi, G., Schena, L., Ippolito, A., and Salerno, M. G. 2005. Incidence of Verticillium wilt on olive in Apulia and genetic diversity of Verticillium dahliae isolates from infected trees. J. Plant Pathol. 87:13-23.

48. Pegg, G. F., and Brady, B. L. 2002. Verticillium Wilts. CAB International, Wallingford, UK.

49. Portenko, I. G., and Akimov, G. I. 1997. Vegetative compatibility among Verticillium dahliae populations of cotton-growing regions of the Middle Asia. Page 93 in: Proc. 7th Int. Verticillium Symp. Athens.

50. Resende, M. L. V., Flood, J., and Cooper, R. M. 1994. Host specialization of Verticillium dahliae, with emphasis on isolates from cocoa (Theobroma cacao). Plant Pathol. 43:104-111.

51. Rodríguez-Jurado, D, and Bejarano-Alcázar, J. 2007. Dispersión de Verticillium dahliae en el agua utilizada para el riego de olivares en Andalucía. Bol. San. Veg. Plagas 33:547-562.

52. Rodríguez-Jurado, D., Blanco-López, M. A., Rapoport, H. E., and Jiménez-Díaz, R. M. 1993. Present status of Verticillium wilt of olive in Andalucía (southern Spain. Bull. OEPP/EPPO Bull. 23:513 516.

53. Rowe, R. C. 1995. Recent progress in understanding relationships between Verticillium species and subspecific groups. Phytoparasitica 23:31-38.

54. Sánchez-Hernández, M. E., Ruiz-Dávila, A., Pérez de Algaba, A., BlancoLópez, M. A., and Trapero-Casas, A. 1998. Occurrence and etiology of death of young olive trees in southern Spain. Eur. J. Plant Pathol 104:347-357.

55. Schnathorst, W. C., and Sibbett, G. S. 1971. The relation of strains of Verticillium albo-atrum to severity of Verticillium wilt in Gossypium hirsutum and Olea europaea in California. Plant Dis. Rep. 9:780-782.

56. Strausbaugh, C. A. 1993. Assessment of vegetative compatibility and virulence of Verticillium dahliae isolates from Idaho potatoes and tester strains. Phytopathology 83:1253-1258.

57. Strausbaugh, C. A., Schroth, M. N., Weinhold, A. R., and Hancock, J. G. 1992. Assessment of vegetative compatibility of Verticillium dahliae tester strains and isolates from California potatoes. Phytopathology 82:61-68.

58. Talboys, P. W. 1960. A culture medium aiding the identification of Verticillium albo-atrum and V. dahliae. Plant Pathol. 9:58-59.

59. Thanassoulopoulos, C. C., Biris, D. A., and Tjamos, E. C. 1979. Survey of Verticillium wilt of olive trees in Greece. Plant Dis. Rep. 63:936-940.

60. Tjamos, E. C., and Jiménez Díaz, R. M. 1998. Management of disease. Pages 55-57 in: A Compendium of Verticillium Wilt in Tree Species. J. A. Hiemstra and D. C. Harris, eds. Posen y Looijen, Wageningen, The Netherlands.

61. Tsor, L., and Levin, A. G. 2003. Vegetative compatibility and pathogenicity of Verticillium dahliae Kleb. isolates from olive in Israel. J. Phytopathol. 151:451-455.

62. Villalobos, F. J., Testi, L., Hidalgo, J., Pastor, M., and Orgaz, F. 2006. Modelling potential growth and yield of olive (Olea europaea L.) canopies Eur. J. Agron. 24:296-303.

63. Wilhelm, S., and Taylor, J. B. 1965. Control of Verticillium wilt of olive through natural recovery and resistance. Phytopathology 55:310-316. 